\title{
Enhancing quality of life through the lens of green spaces: A systematic review approach
}

\author{
Collins Adjei Mensah · Lauren Andres · Upuli Perera · Ayanda Roji
}

\begin{abstract}
Improving citizens' quality of life is a stated priority of many governments in both the global north and south. However, efforts to achieve this often focus on socio-economic measures, with limited attention to the contributions of environmental variables such as green spaces. This paper sought to bridge this knowledge gap by tracing the linkages between green spaces and quality of life, and how these connections can inform policy development in order to assist governments to achieve positive outcomes for quality of life. The paper took a theoretical approach by utilising the systematic review method. In all, 452 publications were included in this review, and rigorous content analysis was employed to retrieve relevant data. Green spaces were found to provide various social, economic, and environmental benefits, which in turn improve physical, psychological, emotional, social, and material wellbeing of individuals and thus enhance quality of life. It is therefore strongly recommended that conservation of green spaces should be integrated into national health, environmental and socio-economic policies in order to promote effective utilisation of green spaces to enhance citizens' overall quality of life.
\end{abstract}

Keywords: quality of life, green spaces, economic, social, environment

\section{Introduction}

The term "quality of life" has been used vigorously across many disciplines, ranging from environmental and health sciences to social sciences. This is due to its complex nature embracing diverse elements that influence human livelihood. The phrase "quality of life" first became popular after the Second World War when it was used to signify "good life," which centred more on issues such as health, employment, housing, the environment, and visual arts (Holmes, 2005; Campbell, 1977). The broad nature of this concept has resulted in different scholars adopting differing definitions and investigating it from different perspectives. For example, from the perspective of social sciences, the effects of different variables such as leisure, wealth, security, employment, housing, education, family ties, cultural values, and community involvement on quality of life have been highly researched (Galloway, 2006). From the domain of health sciences, matters of life expectancy, psychological wellbeing, prevalence of diseases, personal growth, access to healthcare and their relationship with quality of life have also strongly been emphasised (Bakas et al., 2012; Moons et al., 2006). In the environmental sciences, pollution, waste management, and climate change are among the major issues that have been assessed in relation to quality of life (Albouy et al., 2013; Land Use Consultants, 2011; Baud et al., 2001).

These differing perspectives illustrate the extent to which quality of life can be influenced by different variables. However, one area which has not received much research scrutiny is the influence of natural environments or green spaces on quality of life. Despite the general

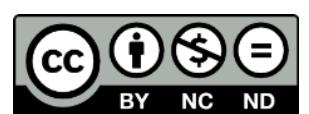

Copyright belongs to the author(s) www.internationaljournalofwellbeing.org 
acknowledgement of green spaces as an important environmental asset which plays a vital role in human life (Wolch et al., 2014; Ernstson, 2012; Saraev, 2012), there is a paucity of research linking green spaces and quality of life, and describing the various contributions that such spaces provide to enhance quality of life.

For the purposes of this review, green spaces are defined as all natural and semi-natural spaces (particularly in urban areas) that are primarily covered by vegetation which are available for human usage. Examples include parks, gardens, woodlands, trees, forests, allotments, and wetlands.

The aim of this paper is to systematically review the existing literature to trace the connections between green spaces and quality of life. Furthermore, it aims at analysing the relationships between green spaces and quality of life from social, environmental, and economic perspectives in order to understand the various ways in which green spaces provide value for human life. The review also seeks to inform policy makers of the relevance of green spaces to human life and the need to give priority to green spaces in policies affecting the quality of life of the general public. For the remainder of this paper, the constituent features that make up the construct of quality of life are discussed in detail to provide a strong theoretical background. Following this, analyses of how green spaces enhance various features of quality of life are examined from social, environmental, and economic perspectives. The paper concludes with key ideas and policy implications of the study's findings to serve as major lessons for future efforts to improve quality of life through the conservation and promotion of green spaces.

\section{Conceptualising quality of life and green spaces}

The term "quality of life" has been subjected to varied definitions and interpretations by different scholars. According to the World Health Organisation (WHO), quality of life is "an individual's perception of their position in life in the context of the culture and value systems in which they live, and in relation to their goals, expectations, standards and concerns" (The WHOQOL Group, 1995: 1405). Meeberg (1993: 34) described quality of life as "an acceptable state of physical, mental, social and emotional health as determined by the individual referred to". In the views of Cella and Nowinski (2002), quality of life focuses on one's physical, functional, social, and emotional wellbeing but not external contributors such as the environment and work influences. Additionally, Harvey (1993) views quality of life to be closely connected with how a person carries out his or her daily routine and the relationship between his or her environment, choices, and behaviour. These views have resulted in no common agreed definition for "quality of life," but, rather, have influenced different sets of elements to underlie quality of life.

Apart from the above broad definitions, "quality of life" has been classified to be influenced by some factors or composed of specific elements. Felce (1996) classified quality of life as being influenced by six broad elements: physical, material, emotional, social, productive, and rights/civic wellbeing. Similarly, a study by Hagerty et al. (2001) found quality of life to be influenced by seven main domains: health, material wellbeing, social inclusion, work and productive activity, emotional wellbeing, personal safety, and relationship with family and friends. This structure is largely consistent with the WHO's categorisation of quality of life into six components: physical wellbeing, environmental wellbeing, psychological wellbeing, social relations, level of independence, and spiritual wellbeing (WHO, 1997). Wellbeing in this context refers to the state of being happy, healthy and comfortable with life (Galloway et al., 2006). In addition to this, a comprehensive assessment of quality of life by Schalock and 
Verdugo (2002) based on 2455 articles found quality of life to be underpinned by eight core domains as shown in Table 1 below (Galloway et al., 2006).

Table 1. Core components of quality of life

\begin{tabular}{ll}
\hline Core domains of quality of life & Indicators \\
\hline 1. Emotional wellbeing & Contentment, self-concept, lack of stress \\
2. Interpersonal relations & Interactions, relationships, support \\
3. Material wellbeing & Financial status, employment, housing \\
4. Personal development & Education, personal competence, performance \\
5. Physical wellbeing & Health, leisure, activities of daily living \\
6. Self determination & Autonomy/personal control, goals and personal values, \\
& choices \\
7. Social inclusion & Community integration and participation, community \\
& roles, social support \\
8. Rights & Human and civil rights \\
\hline
\end{tabular}

Source: Galloway et al. (2006)

These different views have led to differing ways of conceptualising quality of life. For example, Lindstrom (1994), relying more on public health and hierarchical approach modelled quality of life on four spheres: global, external, interpersonal, and personal. These spheres are closely connected to each other and designed to serve all manner of people, thus earning the name universal quality of life model (Table 2 below).

Table 2. Universal quality of life model

\begin{tabular}{|c|c|c|}
\hline Spheres & $\begin{array}{l}\text { Dimensions } \\
\text { (Objective } \mathcal{E} \text { subjective) }\end{array}$ & Examples \\
\hline $\begin{array}{l}\text { Global: ecological, societal } \\
\text { and political resources }\end{array}$ & $\begin{array}{l}\text { 1. Micro environment } \\
\text { 2. Culture } \\
\text { 3. Human rights } \\
\text { 4. Welfare polices }\end{array}$ & $\begin{array}{l}\text { Physical environment, } \\
\text { respect for human rights, } \\
\text { equity, resource allocation. }\end{array}$ \\
\hline $\begin{array}{l}\text { External: social and } \\
\text { economic resources }\end{array}$ & $\begin{array}{l}\text { 1. Work } \\
\text { 2. Income } \\
\text { 3. Housing }\end{array}$ & $\begin{array}{l}\text { Education, employment, } \\
\text { economy, standard of } \\
\text { housing. Satisfaction with } \\
\text { these conditions. }\end{array}$ \\
\hline $\begin{array}{l}\text { Interpersonal: resources in } \\
\text { social relations and support }\end{array}$ & $\begin{array}{l}\text { 1. Family structure } \\
\text { 2. Intimate friends } \\
\text { 3. Extended social support }\end{array}$ & $\begin{array}{l}\text { Size of family, friends, } \\
\text { intimate relationships, } \\
\text { support from neighbours } \\
\text { and society. Satisfaction } \\
\text { with above. }\end{array}$ \\
\hline Personal: personal resources & $\begin{array}{l}\text { 1. Physical } \\
\text { 2. Mental } \\
\text { 3. Spiritual }\end{array}$ & $\begin{array}{l}\text { Growth, activity, self- } \\
\text { esteem and basic mood, } \\
\text { meaning of life. }\end{array}$ \\
\hline
\end{tabular}

Source: Lindstrom (1994)

This model starts with the personal sphere representing physical, mental and spiritual dimensions of human beings which are experienced in the context of social relationships and 
support (the interpersonal sphere) (Lindstrom \& Eriksson, 2010). The outcome of this has socio-economic effects (external sphere) and global influences such as a society and its culture in a geophysical context (global sphere).

Building on Lindstrom's (1994) model, Felce and Perry (1995) further conceptualised quality of life not to have a hierarchical approach but rather to result from dynamic interaction between objective life conditions, subjective feelings of wellbeing, and personal values and aspirations. These three elements are capable of changing independently due to external influences such as peers, material inheritance, age and maturation, employment, and other social, economic, and political variables (Figure 1 below).

Figure 1. Model of quality of life

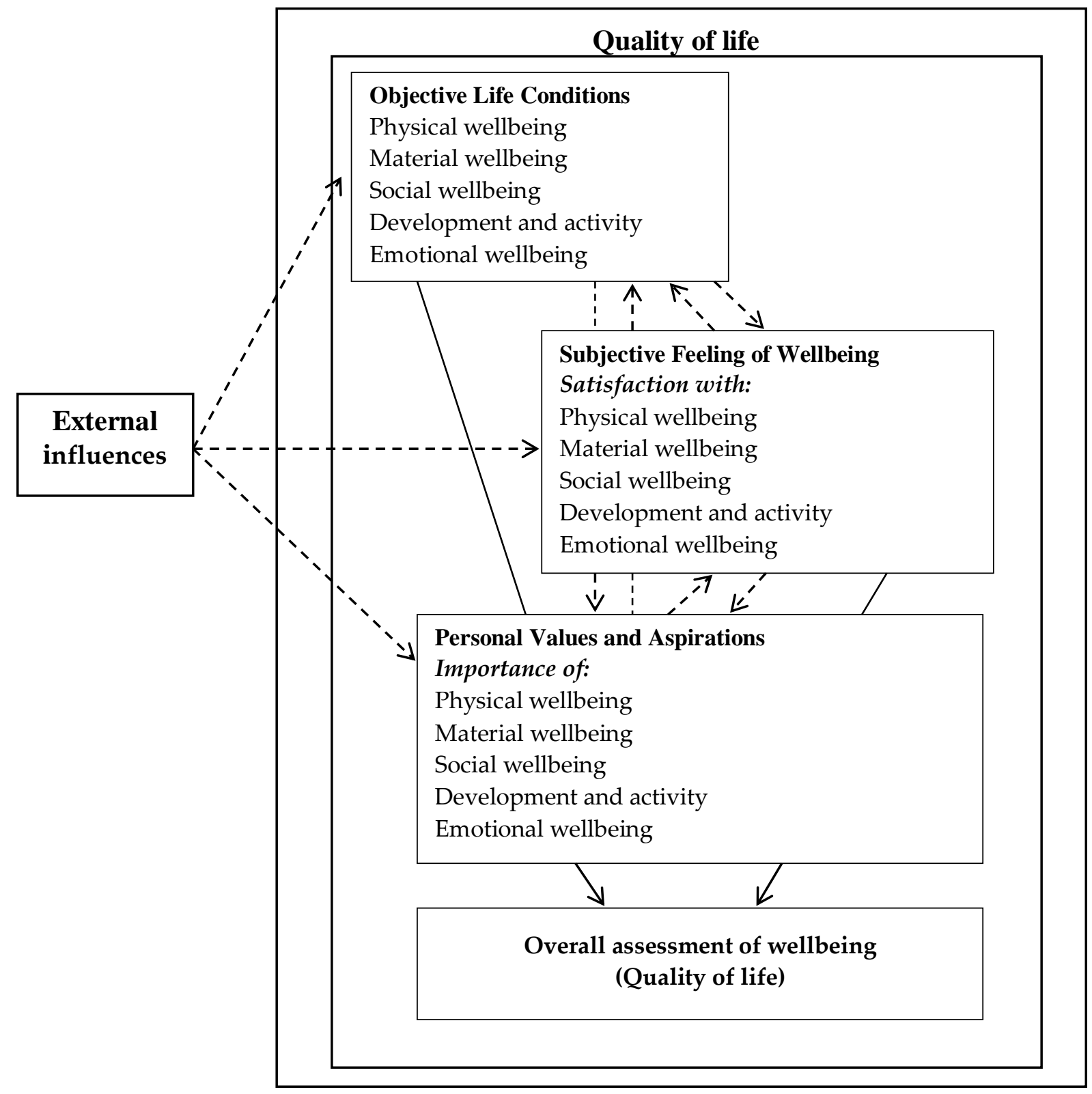

Source: Felce and Perry (1995) 
In addition to this, Ventegodt et al. (2003) conceptualised quality of life as a spectrum (integrated model) ranging from subjective to objective dimensions, with existential elements placed in the middle to connect both the subjective and objective facets (Figure 2 below). The existential elements in this context represent the depth of one's life. With reference to this model, "wellbeing" and "objective factors (such as cultural norms)" are superficial in nature because they are at the outer edges of the model and deal with an individual's limited ability to adapt to a given culture, whilst "satisfaction with life" and "fulfilment of needs" elements are concerned with the deeper aspects of one's life. "Happiness" and "realisation of life potential" encompass a person's deepest existence and nature as a human being, with the "meaning in life" and "biological order" components (order and disharmony in the biological information system) dealing with one's innermost being.

Figure 2. Integrative model of quality of life

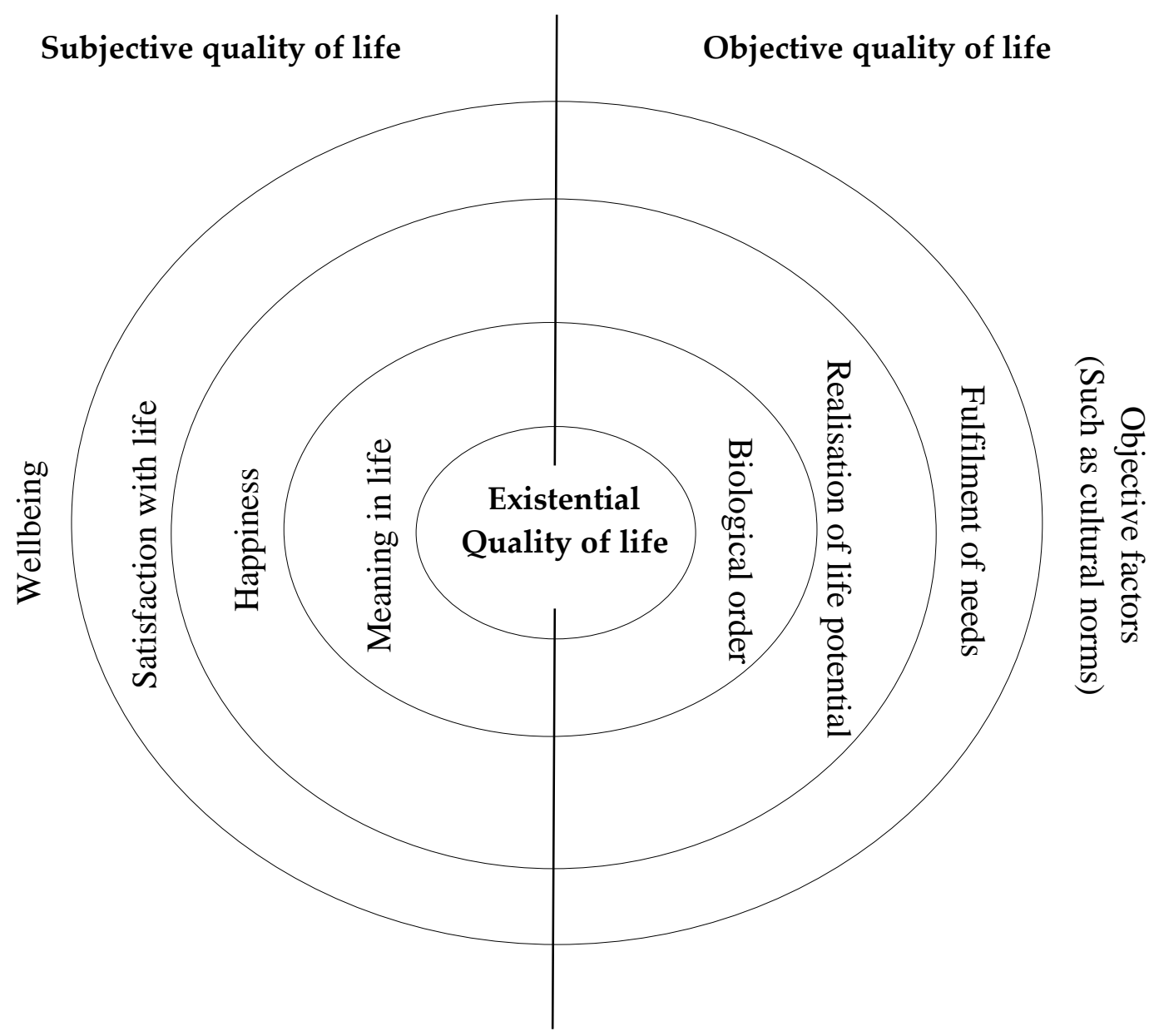

Source: Ventegodt et al. (2003)

If we attempt to assimilate the various components or elements of quality of life that have been identified in the literature reviewed above, it can be deduced that quality of life has both subjective and objective dimensions (Moons et al., 2006; Susniene \& Jurkauskas, 2009; Muldoon et al., 1998; Felce, 1997; Testa \& Simonson, 1996). The subjective dimension deals with individuals' level of satisfaction with their personal lifestyle (Ventegodt et al., 2003; Albrecht \& Devlieger, 1999; Felce \& Perry, 1995). It relates to one's personal circumstances and is achieved through a person's evaluation of the extent to which he/she is content with life. The objective 
dimension relates to how a person's life is perceived by the outside world (Moons et al., 2006). It is concerned with fulfilling the societal and cultural demands for material wealth, social status, and physical wellbeing. This objective dimension concentrates on observable, external life conditions of a person influenced by the culture or environment in which one finds him or herself. Critics have raised concerns about the lack of consistent definitions for many of the proposed constituents of quality of life such as happiness, satisfaction in life, spiritual wellbeing, and emotional wellbeing (Holmes, 2005; Skevington et al., 2004; Bowling, 1995; Rosenberg, 1995). Due to their subjective nature and variations among different cultures in terms of the expectations and acceptable standards that operate in a particular community, universally applicable definitions for these traits remain elusive.

In sum, quality of life can be said to be a construct involving both subjective and objective aspects of an individual's lifestyle which constitute physical, social, emotional, psychological, and material wellbeing. Hence, to achieve a better quality of life, one's physical, social, emotional, psychological, and material wellbeing has to be improved at an appreciable level. Physical wellbeing is the "ability to be fully engaged, on a regular basis, in all developmentally appropriate activities" (Cole, 2006:1). Emotional wellbeing covers the capacity to understand and regulate emotions in a healthy and adaptive way, whilst psychological wellbeing signifies how happy or content a person feels with life (Felce \& Perry, 1995). Social wellbeing, on the other hand, refers to healthy interpersonal relations with family and community members, and material wellbeing focuses on the acquisition of material things that enable one to act meaningfully to pursue his/her goals and enjoy life (Felce \& Perry, 1995).

\subsection{The concept of green spaces}

Although there are multiple definitions of "green spaces" in the literature, the term is used to broadly cover those physical environments with some degree of vegetation cover. Fratini and Marone (2011) used the term "green spaces" to describe areas that are naturally or artificially covered with vegetation. Fam et al. (2008) define green spaces as all vegetative spaces, including all areas that have trees, shrubs, and grasses. According to Baycan-Levent et al. (2002), green spaces are public or private urban areas, primarily covered by vegetation which are directly or indirectly available to users, whereas Dunnett et al. (2002) use the term to refer to lands that are made up mainly of unsealed, permeable, "soft" surfaces such as soil, grass, shrubs, forests, parks, gardens, wetlands, and trees which are privately or publicly accessible or managed. Cilliers (2013), dwelling on the works of Tzoulas et al. (2007) and Sandstrom (2002), used the term "green spaces" to refer to entire green infrastructure which covers a network of all natural, semi-natural and artificial ecological systems found at all spatial scales within a given area.

Swanwick et al. (2003), in their description of the urban environment, provide a framework which includes green spaces as a component of this environment. According to them, the whole land in an urban area can be broadly divided into two: buildings and external environment (Figure 3). The external environment contains both green and grey spaces. The grey spaces represent the hard land surfaces, covered mostly by concrete, tarmac or asphalt, with examples being town squares, plazas, esplanades, and roads. Those aspects of the grey spaces used for specific functions such as roads, pavements, and car parks are classified as functional grey spaces, whilst those planned basically for public enjoyment, such as town squares, plazas, and esplanades are termed civic grey spaces. According to Swanwick et al. (2003) and Dunnett et al. (2002), green spaces cover soft land surfaces and can be in the form of a liner feature (e.g. trees along transport routes), semi-natural (wetlands, woodland), functional 
(allotments, churchyards, school grounds), and amenity (parks and gardens) features. Both green and grey spaces together constitute urban open spaces, with those having public access classified as public open spaces.

Figure 3. Conceptualisation of green spaces

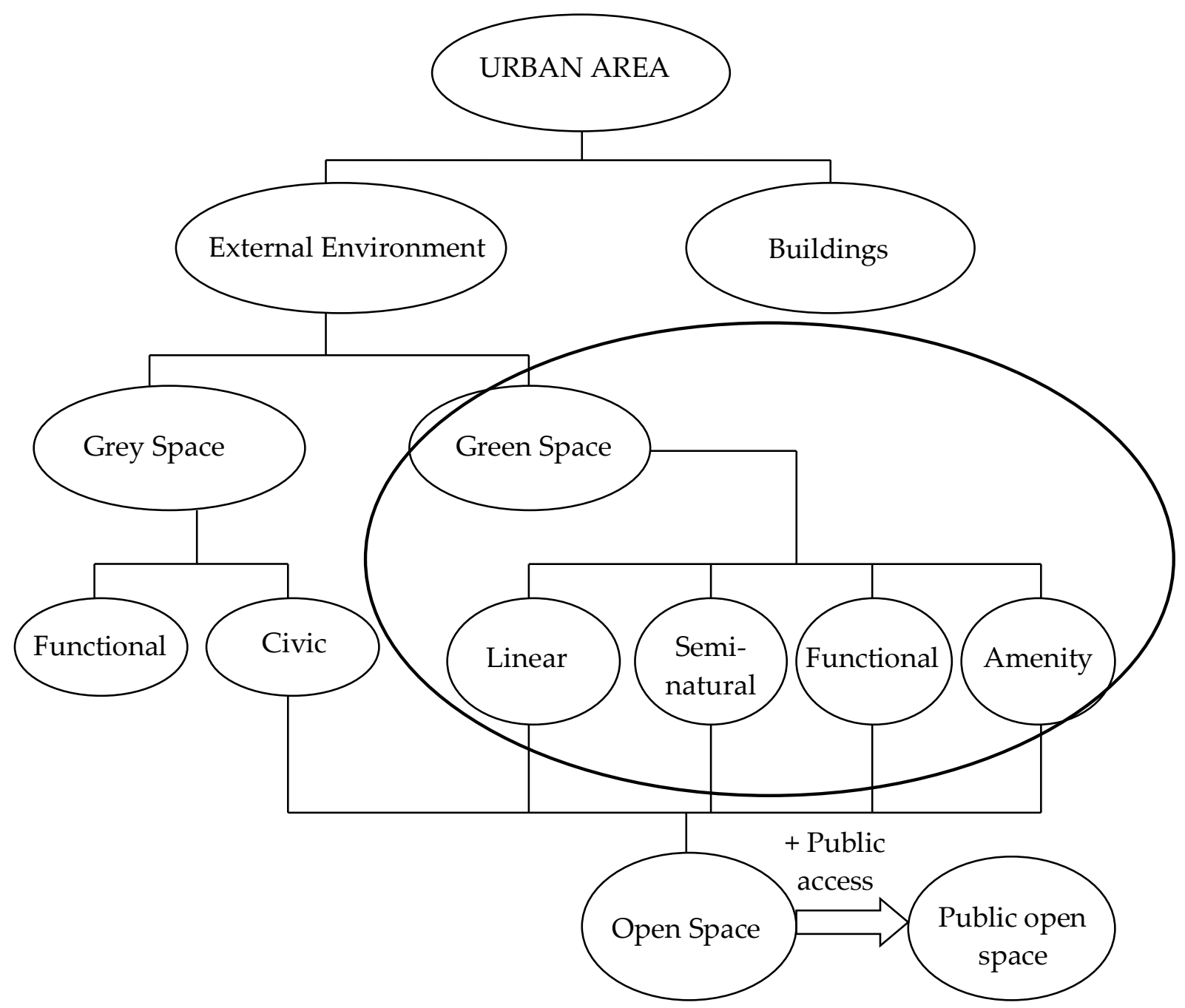

Source: Swanwick et al. (2003)

It can therefore be inferred from the above descriptions that green spaces are chiefly defined by the availability of green vegetation and therefore cover all spaces or land that have some form of vegetation, either natural or artificial, for human usage.

\section{Materials and Methods}

The paper is a systematic review of published scholarly works on green spaces and quality of life. The broad nature of the study and the need to gather enough evidence to trace the linkages between green spaces and quality of life made this approach the appropriate choice. The systematic review approach entails the usage of an explicit approach to search, appraise and synthesise available literature to satisfy the aim of the topic under study (Victor, 2008; Akobeng, 2005). It organises all theoretical and empirical works that fit pre-specified criteria to answer a specific research question. The robust and comprehensive nature of the systematic review helped the study avoid bias in the analysis of results, allowed a wide range of data to be 
assimilated, and provided more accurate and reliable conclusions, since the data utilised had already been tested in other studies (Victor, 2008; Akobeng, 2005). Books, journals, conference papers, and reports that were related to the topic under study were included in the review. In accordance with the work of Uman (2011), Victor (2008), Coren and Fisher (2006) and Khan et al. (2003), the following processes were undertaken to retrieve data from secondary sources and analyse them for presentation.

1) Formulating a question to guide the review: This stage dealt with framing a question to capture the main problem and purpose of the study. It was done to make the review well-structured and focus on the topic under study. The broad question posed to underlie the review was as follows: In what ways do green spaces enhance quality of life? Further to this broad question, sub-questions were formulated to guide the selection of publications for the study. These sub-questions were:

- What benefits are derived from green spaces?

- How do such benefits improve or enhance various features or elements of quality of life?

Figure 4 below provides a flow chart illustrating the nature of the review question and its underlying structure for inclusion in the study.

Figure 4. Review question and its underlying structure

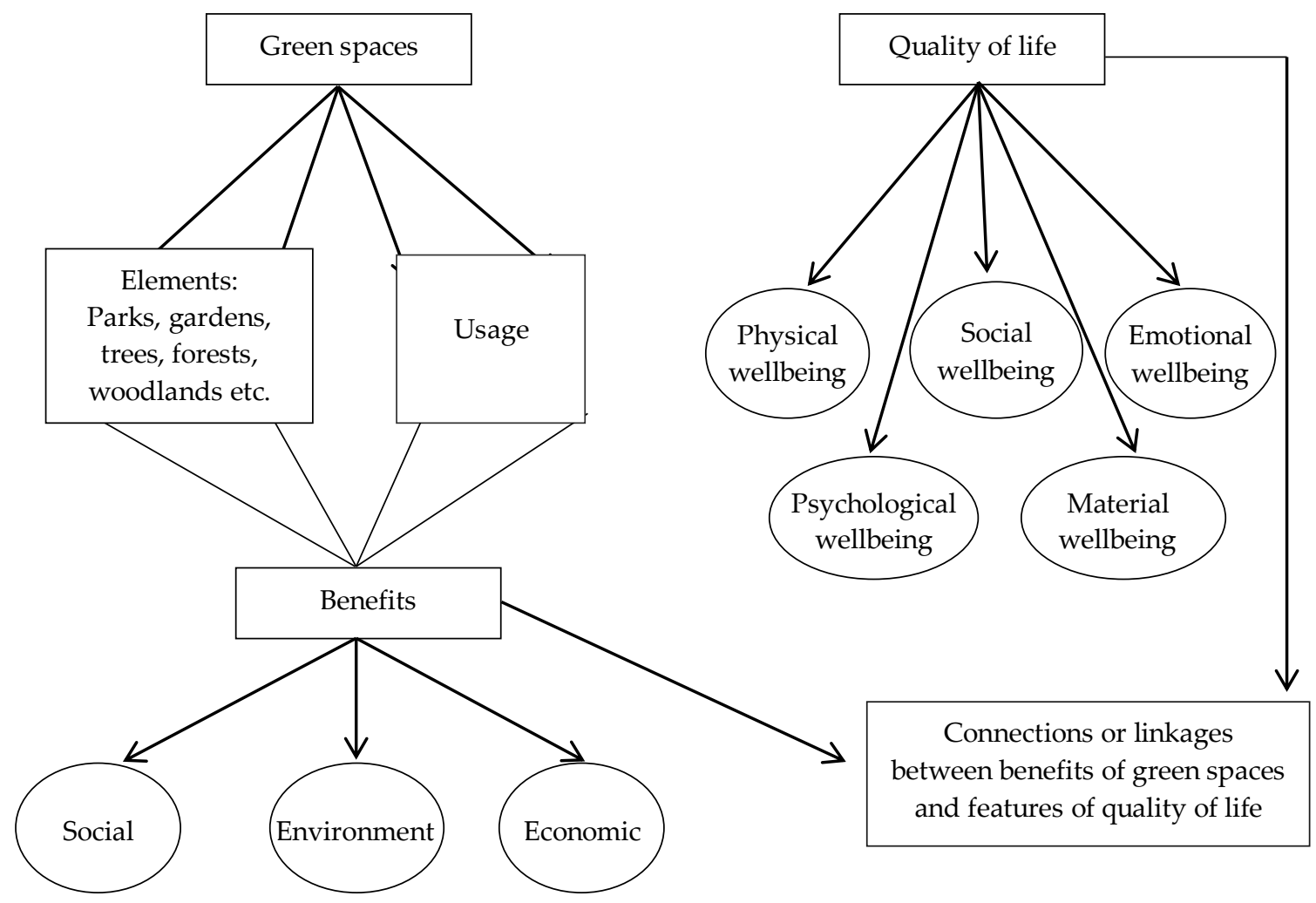

2) Identifying relevant publications on the topic under study: Much effort was made to gather many relevant publications for the study. The following databases were searched to identify studies on green spaces and quality of life: Science Direct, Social Science Research Network, Google Scholar, Thomson Reuters, Directory of Open Access Journals (DOAJ), JSTOR, Ingenta Connect, Web of Science, and Scopus. Various internet engines such as Google, Yahoo, Bing and Ask.com were also 
searched for further materials. This electronic search was supplemented with a manual search for additional hard copy materials from the University of Birmingham (UK) library. A total of 1,428 publications or studies were found, but review of these publications and their relevance to the review questions as formulated above reduced this to 639 publications to be considered for the study.

3) Assessing the quality of selected publications: After identifying the specific publications for inclusion in the study, their level of quality was assessed according to the six quality assessment criteria as described by Bowler et al (2010). Much emphasis was also given to peer-reviewed works. This resulted in 452 publications being selected for final inclusion in the study.

4) Analysis and synthesis of evidence: Rigorous content analysis was performed on the final selected publications. The various findings from these studies were then collated and analysed to serve as the findings of the study. Table 3 below summarises the key findings that were obtained on the interrelationship between green spaces and quality of life. 
Table 3. A summary of ideas on the linkages between green spaces and quality of life

Benefits of green spaces
Environmental
Enhances local climate
Improves air quality
Conserves biodiversit

Social perspective

Leisure \& recreation

Child development

Health benefits

Social cohesion

National heritage \& culture

Education

Crime control

Human rights

Economic

Job opportunities

Revenue to governments

Attracts business \& tourism

Minimises health expenses
Connection with quality of life

Strength

Ameliorate local climate to protect human beings from harsh weather conditions and related physical problems - physical wellbeing.

Minimise the effects of air pollution on human health - physical wellbeing.

Provide a range of ecosystem services for human survival -physical and psychological wellbeing.

Create happiness to support physical and psychological wellbeing

Support physical and emotional development of children.

Ameliorate problems such as stress, depression, obesity, and diseases associated with physical

inactivity to enhance physical, emotional and psychological wellbeing.

Create avenues for different outdoor social functions that promote high sense of belongingness Strong and social inclusion. Support social wellbeing.

Promote high sense of cultural identity and social connectedness which enhance social, and psychological wellbeing.

Information and research on natural and environmental process. These support social and psychological wellbeing.

Minimise psychological precursors to violence and increase surveillance of properties around them. Support psychological wellbeing.

Promote environmental justice (equity or fair access to environmental resources) to enhance psychological wellbeing.

Income to acquire basic needs and other material things to enhance human livelihood - physical Strong and material wellbeing.

Financial support to governments to aid infrastructural development for human welfare -

Moderate physical wellbeing.

Help individuals to engage in different economic activities to earn a living - physical and

Moderate material wellbeing

Help to save money on health problems - physical and psychological wellbeing 


\section{Linkages between quality of life and green spaces}

This section of the paper presents the general findings of the study. It explores the associations between green spaces and quality of life from social, economic and environmental perspectives. It outlines evidence demonstrating the important contributions of green spaces to human livelihood and how such contributions enhance quality of life in general. Much emphasis was given to green spaces in urban areas, referred to as "urban green spaces".

\subsection{Social perspective}

Green spaces provide a venue for leisure and recreational activities, which are associated with enhanced quality of life. Jim and Chen (2006) claim that the recreational and amenity benefit of urban green spaces is one of the most predominant social benefits that people derive from using urban green spaces. Lloyd and Auld (2002) found various happiness enhancing leisure activities such as observing nature, merrymaking, relaxing, and sporting activities to strongly depend on resources such as green spaces. Observations in China by Xi-Zhang (2009) and Jim and Chen (2006) revealed that many urban residents use green spaces for recreational activities such as relaxing, playing with children, walking pets, exploring, and observing wildlife. Manlun (2003) found the majority of middle and low income earners in countries in both the global north and south using parks and public gardens as spaces for socialising, relaxing, exercise, and enjoying the natural environment. A study by Harnik (2004) showed that in the USA over 12 million people and 25 million people visit Lincoln Park in Chicago and the Central Park in New York respectively for various reasons, with recreational activities being the dominant purpose. The green spaces in these instances serve as a natural resource that provides a setting for various recreational activities which have a positive effect on individuals' happiness and therefore enhance quality of life (Ventegodt et al., 2003; Lloyd \& Auld, 2002).

Aside providing an environmental setting for leisure and recreation, green spaces improve quality of life by providing opportunities to enhance the physical and emotional development of individuals, especially children (Lowman, 2006). A study by the Association for Childhood Education International found that playing in parks and other green spaces helps the development of children's muscle strength, co-ordination, language, cognitive thinking, and reasoning abilities (Isenberg \& Quisenberry, 2002). It has further been revealed that observing green spaces such as forests gives children opportunities to enhance their analytical and strategic thinking, and improve their cognitive development (Cornell et al., 2001). This promotes improved quality of life for children through supporting their healthy physical development.

In addition, green spaces contribute positively to improve the physical and mental health of individuals, which enhances quality of life in several ways. Research has shown that exposure to green spaces improves psychological wellbeing (Ernstson, 2012; Barton \& Pretty, 2010; Maas et al., 2009), alleviates stress (Woo et al., 2009), and reduces some mental disorders in children such as Attention Deficit Hyperactivity Disorder (Louv, 2005; Taylor et al., 2001). The use of urban green spaces for physical activities such as walking, jogging, playing football, and other sporting activities helps to address the problem of obesity and also plays a role in preventing diseases such as cardiovascular disease, musculoskeletal diseases, stroke, and cancer (CJC Consulting, 2005). Studies have revealed that the usage of parks by the elderly for physical activities is associated with increased fitness, decreased incidence of chronic age-related diseases, and increased life span (Milligan et al., 2004; Takano et al., 2003). These benefits enhance quality of life by supporting the physical, emotional, and psychological wellbeing of individuals. 
In the area of education, Sorensen et al. (1997) found that green spaces such as botanical gardens, natural trails, and zoos provide a venue for educating people about different forms of flora and fauna, and offer opportunities for individuals and families to learn about the environment and natural processes. Conner (2005) stressed that different forms of urban green spaces used for research activities in universities, and scientific and industrial research organisations help to examine a wide range of biophysical, economic, and cultural issues related to the natural environment. Fam et al. (2008) gave an example of the educational benefits of green spaces by citing the Museum of Economic Botany in the Adelaide Botanical Gardens, which has been used for several studies relating to the natural environment. In this way, green spaces can support both formal and informal education, which are variables that contribute to an individual's overall quality of life (Lindstrom \& Eriksson, 2010; Lindstrom, 1994).

An association has also been established between access to green spaces and enhancement of social interaction, inclusion, and cohesion. A study by Cohen et al. (2008) concluded that there is a positive association between neighbourhood parks and the likelihood of residents interacting positively. Green spaces such as community parks and gardens provide an environment where different categories of people, including those who are frequently excluded from social interaction, such as the disabled or the elderly, can socialise (Fan et al., 2011). This helps to promote social inclusion and cohesion. Moreover, Kim and Kaplan (2004) indicated that green spaces and other natural features play an important role in attaching and connecting people to the area they live in and their local community. Social connectedness promoted by green spaces helps individuals to develop a sense of belonging and good interpersonal relationships with others that supports social wellbeing, which is one of the domains of quality of life.

On a larger scale, green spaces can contribute to the conservation of national heritage and culture, and thus have impact on the community's quality of life. According to the Urban Green Space (UGS) Taskforce (2002), some urban green spaces provide venues for many national and cultural ceremonies, such as local festivals, musical interludes, civic celebrations, and other cultural events. In addition, urban green spaces sometimes contain historic and cultural artefacts such as burial grounds, monuments, fountains, and pavilions, which help to preserve culture and national heritage (BOP Consulting, 2012; UGS Taskforce, 2002). Studies on culture and quality of life have found that engagement in cultural activities enhances one's cultural identity, community participation, sense of purpose, social connectedness, and empowerment (Galloway, 2006; Coffman, 2002). By providing venues for cultural activities and national traditions to be celebrated, green spaces support the social, emotional and psychological wellbeing of both individuals and communities, and thus enhance quality of life.

Green spaces also have an acknowledged role in supporting human rights, particularly environmental justice (equitable access to environmental resources). The connection between green spaces and environmental justice hinges on the even distribution of green spaces in an area, facilitating equitable access to the natural environment (Kabischa \& Haase, 2014; Wolch et al., 2014; Sister et al., 2010). In this case, even distribution of green spaces in communities enhances environmental justice, as it helps all people, irrespective of their status, gender, race, and ethnicity, to have fair access to natural vegetation and enjoy the qualities of nature. Conversely, uneven distribution of green spaces may contribute to environmental injustice (Davis et al., 2012; Dai, 2011; Jennings et al, 2012). Therefore, green spaces supporting environmental justice help to enhance quality of life, as it protects individuals' right to enjoy a clean and healthy environment. A positive relationship between green spaces and crime 
control is also observed. Studies show that property crime and vandalism rates are lower in properties which have green spaces (parks, gardens, lawns, and well-spaced trees) around them (Donovan \& Prestemon, 2012; Lorenzo \& Wims, 2004; Kuo \& Sullivan, 2001). It is proposed that the use of green spaces for various recreational activities may mitigate psychological precursors to crime and violence. Furthermore, the public use of green spaces may increase surveillance on nearby properties and make such properties less easily targeted by burglars (Kuo \& Sullivan, 2001).

\subsection{Environmental perspective}

From an environmental perspective, green spaces were found to offer several benefits in providing a healthy environment, which further supports quality of life. Green spaces were observed to contribute positively in regulating local urban climate (Konijnendijk et al., 2013; Fam et al., 2008; Kottmeier et al., 2007). The presence of many non-permeable surfaces in urban areas such as asphalt, pavement, and concrete increases the absorption of solar radiation and causes an increase in surface temperature. The heat from such hard surfaces is then radiated back, which contributes to an increase in local temperature around built-up areas known as the "urban heat island" effect. Different studies show that conserving many urban green spaces helps decrease absorption of solar radiation from the land surface and increase evapotranspiration, which has the effect of cooling down urban temperatures and consequently modifying the climate in these areas (Konijnendijk et al., 2013; Alexandri \& Jones, 2008; Fam et al., 2008; Kottmeier et al., 2007; McPherson \& Muchnick, 2005; Gomez et al., 2004). This assists in controlling many heat related problems, such as the easy spread of infectious diseases, skin problems, and deaths associated with excessive heat (especially those connected to cardiovascular and respiratory disease, particularly among elderly people) (WHO, 2014).

Improving urban air quality is another major positive environmental contribution of urban green spaces to quality of life (Konijnendijk et al., 2013; Getter \& Rowe, 2006; Nowak et al., 2006). A study conducted in an urban area where most of the buildings had green vegetation on their roofs showed considerable reduction of sulphur dioxide and nitrous oxide in that area (Getter \& Rowe, 2006). A modelling experiment carried out in 48 states in the USA by Nowak et al. (2006) indicated that the atmospheric levels of pollutants such as carbon monoxide, nitrogen oxide, and sulphur dioxide could be reduced by the presence of many urban trees. This shows that the presence of such green spaces helps to intercept the movement of some pollutants and consequently minimise the rate of air pollution. Parks also act as major "carbon sinks" which absorb carbon dioxide from the atmosphere (Davies et al., 2012; Paoletti et al., 2011; Kordowski \& Kuttler, 2010). Hence, the availability of many green spaces such as parks, trees and forests helps to minimise the effects of air pollution on human health.

The preservation of biodiversity of both plants and animals by green spaces supports the individual's quality of life from a different perspective. Studies on the urban environment have shown that different forms of urban green spaces contain significant amounts of biodiversity (Alvey, 2006; Cornelis \& Hermy, 2004; Godefroid \& Koedam, 2003; Jim \& Liu, 2001). About 1,300 species of flora in rich quantities were found in some green spaces around the city centre of Rome by Bonnes et al. (2004). Cornelis and Hermy (2004) in a survey of 15 parks in urban areas in Flanders (Belgium) concluded that those parks contain about 30\%, 50\% and $60 \%$ of all wild plants, birds and amphibians in Flanders respectively. A study undertaken in the UK revealed that golf courses have a high volume of tree species and provide a habitat for many species of birds (Tanner \& Gange, 2005). The biodiversity conserved by green spaces helps to protect many organisms such as fungi, bacteria, inserts, and plants, which form vital parts of 
many ecosystems on which human beings depend for their survival. Among the services provided by ecosystems for human survival are the production of food, water, and medicine; support for nutrient cycles and crop pollination, and regulation of floods and erosion.

\subsection{Economic perspective}

In the economic realm, green spaces provide employment opportunities and therefore income for many individuals. Sorenson et al. (1997) found urban greening projects to be often labourintensive and to provide both temporary jobs (soil preparation, planting, etc.) as well as more permanent jobs (maintenance, management, etc.). The turf grass industry in Australia, which provides turf grass to be grown on many urban parks, employs around 80,000 people in different capacities (Aldous, 2005). A study by Blue Sky Green Space (2011) revealed that there are over 50,000 people who are directly employed within public parks and gardens in the UK, and many others who are employed in industries associated with green spaces, such as the manufacture of park-based equipment and products. In Africa, a study by Djibril et al. (2012) found a total of 335 people employed under the department in charge of managing urban green spaces in Abidjan (Cote D'lvoire). As at June 2014, Johannesburg City Parks and Zoo engaged the services of 1,689 employees to work in different capacities to manage the green spaces in Johannesburg, South Africa (Johannesburg City Parks and Zoo, 2014). These employment opportunities created by green spaces contribute to the economic stability of communities by providing income for individuals within the community to acquire both basic and material needs for living.

Green spaces also generate revenue for governments, which aids in the provision of infrastructural developments such as roads, schools, electricity, and health facilities (hospitals and clinics) to support the wellbeing of the citizenry. This is realised through the increase in property values of properties around green spaces, as such properties with higher values pay higher property rates/taxes, which contribute to local government funds. A study in Oregon concluded that houses that were close to natural park areas had higher prices than those that were further away (Lutzenhiser \& Netusil, 2001). Similar findings were made in a study of three towns in the Netherlands (Emmen, Apeldoorn and Leiden), where houses sited near parks had higher property values than those located further away from them (Luttik, 2000). This high property value is found to increase government revenue and thus support different government projects. For example, in Ontario (USA), a statistical analysis of the data of two neighbourhoods showed that the property values of houses around green spaces increased substantially and this helped the government to have an increase in property tax revenue of about $8 \%$ (Crompton, 1999). A similar trend was found in a study in Philadelphia (USA). In this case, the overall increase in tax revenue that the government received as a result of the increase in property value of houses close to green spaces was more than $\$ 18$ million (The Trust for Public Land, 2008). These generated revenues enable governments to invest in infrastructure projects and many economic development initiatives which may further improve the welfare of the general public.

Further economic benefits of green spaces were found in increased business activities around these spaces. Studies have shown that well-planned and maintained green spaces can help to improve an area's image and attract businesses, customers, employees, and different services which create a good business environment and boost local business investment (Saraev, 2012; Land Use Consultants, 2004; DoE \& The Association of Town Centre Management, 1997). In addition, it was noted that the creation of green spaces such as community forests, botanical gardens, and zoos, and the greening of community centres 
attracts tourists, whose spending generates income for local businesses (Saraev, 2012; Aiello et al., 2010). In this respect, green spaces provide an environmental context in which local businesses can thrive. These local businesses provide goods and services to the local community and a source of income and financial security for both their owners and employees, and thus contribute to improving quality of life of many individuals.

It has also been proposed that the health-promoting effect of green spaces is sufficient to result in savings in healthcare costs on a national basis. For example, a study by Blue Sky Green Space (2011) in the UK found that the health benefits provided by the increased physical activity opportunities in Regents Park could result in estimated annual savings of $£ 3.1$ million in healthcare costs to the national government and further annual savings of $£ 463,000$ to the National Health Service. A survey in Sacramento City, California (USA) reported medical savings of about $\$ 19,872,000$ in 2007 due to active engagement of the residents in the city's parks for various physical activities (The Trust for Public Land, 2009). Such savings on health at the national level help governments to get additional income to invest in their economies to improve the livelihood of the general public. At the individual level, it helps people to obtain extra money to acquire more material things for their lives (material wellbeing), which is an important element of quality of life (Galloway et al., 2006; Felce \& Perry, 1995).

Focusing on the benefits of green spaces, the United Nations Environment Programme (UNEP; 2011) has constructed a model illustrating the connections between the social, economic, and environmental benefits of green spaces and quality of life (Figure 5). This model was based on the 2005 Millennium Ecosystem Assessment Report. The environmental benefits of green spaces in this model include provision of a range of ecosystem services such as food, clean water, carbon sequestration, and controlling erosion. The economic benefits include providing employment opportunities and supporting local businesses, whilst the social benefits focus on supporting the housing, health and recreational needs of the people. These benefits improve human wellbeing or quality of life, as shown in Figure 5 below.

\section{Figure 5. Linkages between green spaces and quality of life}

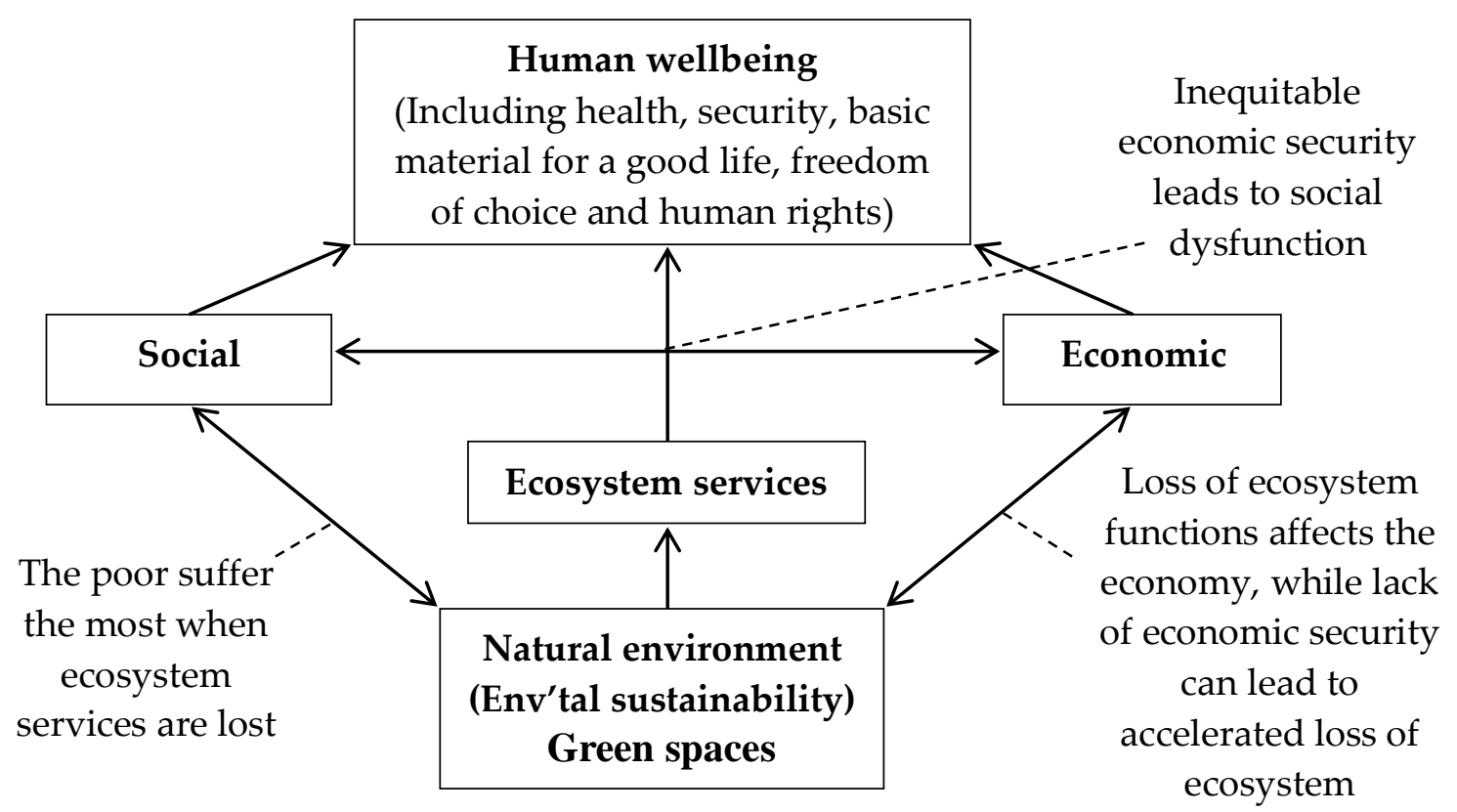

Source: Adapted from UNEP (2011) 


\section{Policy implications}

The findings outlined above lead to several recommendations that should inform government policies in order to improve citizens' quality of life. The myriad social, economic, and environmental benefits of green spaces and their consequent effects on quality of life make these spaces an important consideration in the formulation of government policies and strategies on sustainable development. Sustainable development broadly involves the maintenance of environmental resources (environment pillar); addressing the social needs of people to improve their welfare (social pillar); and ensuring efficient use and allocation of resources to achieve economic growth (economic pillar) to improve the quality of life of people. Green spaces, therefore, through their numerous benefits, help to achieve these pillars of sustainable development. This makes it imperative for green spaces to be prioritised in all policies on sustainable development.

Furthermore, there is a need to consider the conservation and promotion of green spaces in the formulation of public health policies. Evidence from the literature showed that the availability of green spaces in a given area provides many health benefits to the general public. Therefore, including the provision of green spaces in existing public health programmes may help to address common public health problems such as physical inactivity, depression, stress, and obesity. Economic modelling indicates that this would enable national health agencies and governments to save significant amounts of money in the provision of healthcare services. Green spaces should also be given consideration as a resource supportive of education. Studies show that children learn a lot through the forms of play activities which take place in green spaces, such as parks and gardens (Lowman, 2006; Isenberg \& Quisenberry, 2002). Such play activities have positive effects on physical development, cognitive development, muscle strength, co-ordination, language, and the strategic and analytical thinking of children. In view of this, outdoor playing activities in green spaces can be viewed as supportive of many of the aims of the traditional educational curriculum for children.

Pursuing environmental safety strategies, together with the conservation of green spaces, serves as another important policy direction. Such initiatives will provide a strong policy framework to achieve healthy and safe environments in which to enjoy the environmental benefits provided by green spaces, such as low air pollution, good local climate, improved air quality, and low crime rates to enhance human security. The economic contributions of green spaces, such as offering employment opportunities, generating revenue, attracting business activities and tourism development make their recognition in the formulation of economic policies also important. Acknowledgement of the economic benefits associated with green spaces will assist with the formulation of policies that foster local business growth and community level economic development.

\section{Conclusion}

Green spaces provide social, environmental, and economic benefits which both directly and indirectly enhance an individual's quality of life. They help to improve physical, psychological, emotional, social and material wellbeing which underlie several models of quality of life. In order for local and national governing bodies to promote a high level of quality of life amongst their constituents, green spaces should be recognised as important resources, and policies instituted must promote and conserve such spaces. At the local level, this could be achieved through various planning instruments such as community action plans, development plans, and city by-laws giving priority to the conservation of green spaces. At the national level, 
governments and policy makers should consider green spaces in national policies and strategies on health, environment, education, and social welfare.

\section{Authors}

Collins Adjei Mensah

University of Cape Coast

collinsadjeimensah@gmail.com

Lauren Andres

University of Birmingham

Upuli Perera

University of Birmingham

Ayanda Roji

Johannesburg City Parks and Zoo

\section{Publishing Timeline}

Received 23 June 2015

Accepted 10 February 2016

Published 14 May 2016

\section{References}

Aiello, D., Cheung, N., Chow, A., Cofie-Godwin, K., Kwon, N., Lee, S. H., ... Wantz, E. (2010). Measuring the economic impact of green space in Pittsburgh. Pittsburgh, PA: Center for Economic Development, H. John Heinz III College, Carnegie Mellon University.

Akobeng, A. K. (2005). Understanding systematic reviews and meta-analysis. Archives of Disease in Childhood, 90(6), 845-848. http://dx.doi.org/10.1136/adc.2004.058230

Albouy, D., Graf, W., Kellogg, R., \& Wolff, H. (2013). Climate amenities, climate change, and American quality of life. Cambridge, MA: National Bureau of Economic Research. http://dx.doi.org/10.3386/w18925

Albrecht, G. L., \& Devlieger, P. J. (1999). The disability paradox: High quality of life against all odds. Social Science in Medicine, 48(8), 977-988. http://dx.doi.org/10.1016/S0277-9536(98)00411-0

Aldous, D. E. (2005). Education and training opportunities for turf management in Australia. Acta Horticulturae, 672, 71-77. http://dx.doi.org/10.17660/ActaHortic.2005.672.6

Alexandri, E., \& Jones, P. (2008). Temperature decreases in an urban canyon due to green walls and green roofs in diverse climates. Building and Environment, 43, 480-493. http://dx.doi.org/10.1016/j.buildenv.2006.10.055

Alvey, A. A. (2006). Promoting and preserving biodiversity in the urban forest. Urban Forestry and Urban Greening, 5(4): 195-201. http://dx.doi.org/10.1016/j.ufug.2006.09.003

Bakas, T., McLennon, S. M., Carpenter. J. S., Buelow, J. M., Otte, J. L., Hanna, K. M., ...Welch, J. L. (2012). Systematic review of health-related quality of life models. Health and Quality of Life Outcomes, 10(134), 1-12. http://dx.doi.org/10.1186/1477-7525-10-134

Baud, I., Grafakos, S., Hordijk, M., \& Post, J. (2001). Quality of life and alliances in solid waste management: Contributions to urban sustainable development. Cities, 18(1), 3-12. http://dx.doi.org/10.1016/S0264-2751(00)00049-4

Baycan-Levent, T., Leeuwen, E., Rodenburg, C., \& Nijkamp, P. (2002, September). Development and management of green spaces in European cities: A comparative analysis. Paper presented at the 38th International Planning Congress, Athens, Greece.

Blue Sky Green Space (2011). Understanding the contribution parks and green spaces can make to improving people's lives. http://www.rudi.net/node/22531 
Bonnes, M., Carrus, G., Bonaiuto, M., Fornara, F., \& Passafaro, P. (2004). Inhabitants' environmental perceptions in the city of Rome within the framework for Urban Biosphere Reserve of the UNESCO programme on Man and Biosphere. Annals of the New York Academy of Sciences, 1023(1), 175-186. http://dx.doi.org/10.1196/annals.1319.009

BOP Consulting (2012). 2012 world cities culture report. London: Mayor of London.

Bowler, D. E., Buyung-Ali, L. M., Knight, T. M., \& Pullin, A. S. (2010). A systematic review of evidence for the added benefits to health of exposure to natural environments. BMC Public Health, 10, 456. http://dx.doi.org/10.1186/1471-2458-10-456

Bowling, A. (1995). Measuring health: A review of quality of life measurement scales. Buckingham, United Kingdom: Open University Press.

Campbell, A. (1977). Subjective measures of well-being. American Journal of Psychology, 31, 117-124. http://dx.doi.org/10.1037/0003-066X.31.2.117

Cella, D., \& Nowinski, C. J. (2002). Measuring quality of life in chronic illness: The functional assessment of chronic illness therapy measurement system. Archives of Physical Medicine and Rehabilitation, 83(12 Suppl. 2), S10-S7. http://dx.doi.org/10.1053/apmr.2002.36959

Cilliers, S., Cilliers, J., Lubbe, R., \& Siebert, S. (2013). Ecosystem services of urban green spaces in African countries: Perspectives and challenges. Urban Ecosystem, 16(4), 681-702. http://dx.doi.org/10.1007/s11252-012-0254-3

CJC Consulting (2005). Economic benefits of accessible green spaces for physical and mental health: Scoping study (Final Report for the Forestry Commission, UK). Oxford : CJC Consulting.

Coffman, D. D. (2002). Music and quality of life in older adults. Psychomusicology, 18(1-2), 76-88. http://dx.doi.org/10.1037/h0094050

Cohen, D. A., Inagami, S., \& Finch, B. (2008). The built environment and collective efficacy. Health $\mathcal{E}$ Place, 14(2), 198-208. http://dx.doi.org/10.1016/j.healthplace.2007.06.001

Cole, P. (2006). All children ready for school: Health and physical well-being. Early childhood paper briefing series. Bloomington, USA: Early Childhood Center, Indiana Institute on Disability and Community.

Conner, N. (2005). Some benefits of protected areas for urban communities: A view from Sydney, Australia. Sacramento, CA: California Institute of Public Affairs.

Coren, E., \& Fisher, M. (2006). The conduct of systematic reviews for SCIE knowledge reviews. London, United Kingdom: Social Care Institute for Excellence.

Cornelis, J., \& Hermy, M. (2004). Biodiversity relationships in urban and suburban parks in Flanders. Landscape and Urban Planning, 69(4), 385-401. http://dx.doi.org/10.1016/j.landurbplan.2003.10.038

Cornell, E. H., Hadley, D. C., Sterling, T. M., Chan, M. A., \& Boechler, P. (2001). Adventure as stimulus for cognitive development. Journal of Environmental Psychology, 21, 219-231. http://dx.doi.org/10.1006/jevp.2001.0207

Crompton, J. L. (1999). Financing and acquiring park and recreational resources. Champaign, IL: Human Kinetics.

Dai, D. (2011). Racial/ethnic and socioeconomic disparities in urban green space accessibility: Where to intervene? Landscape and Urban Planning, 102(4), 234-244. http://dx.doi.org/10.1016/j.landurbplan.2011.05.002

Davis, A. Y., Belaire, J. A., Farfan, M. A., Milz, D., Sweeney, E. R., Loss, S. R., \& Minor, E. S. (2012). Green infrastructure and bird diversity across an urban socioeconomic gradient. Ecosphere, 3(11), 1-18. http://dx.doi.org/10.1890/ES12-00126.1

Department of the Environment \& The Association of Town Centre Management (1997). Managing urban spaces in town centres: Good practice guide. London, United Kingdom: HMSO.

Djibril, C., Coulibaly, A., Wang, X., \& Ousmane, D. (2012). Evaluating green space use and management in Abidjan City, Cote D'lvoire. International Journal of Economics and Management Engineering, 2(3), 108-116.

Donovan, G. H., \& Prestemon, J. P. (2012). The effect of trees on crime in Portland, Oregon. Environment and Behavior, 44(1), 3-30. http://dx.doi.org/10.1177/0013916510383238

Dunnett, N., Swanwick, C., \& Wooley, H. (2002). Improving urban parks, play areas and green spaces. London, United Kingdom: Department for Transport, Local Government and the Regions. 
Ernstson, H. (2012). The social production of ecosystem services: A framework for studying environmental justice and ecological complexity in urbanised landscapes. Landscape and Urban Planning, 109(1), 7-17. http://dx.doi.org/10.1016/j.landurbplan.2012.10.005

Fam, D., Mosley, E., Lopes, A., Mathieson, L., Morison, J., \& Connellan, G. (2008). Irrigation of urban green spaces: A review of the environmental, social and economic benefits (CRC for Irrigation Futures Technical Report No. 04/08). Sydney, Australia: Cooperative Research Centre for Irrigation Futures.

Fan, Y., Das, K.V., \& Chen, Q. (2011). Neighborhood green, special support, physical activity and stress: Assessing the cumulative impact. Health \& Place, 17, 1202-1211.

http://dx.doi.org/10.1016/j.healthplace.2011.08.008

Felce, D. (1997). Defining and applying the concept of quality of life. Journal of Intellectual Disability Research, 41, 126-135. http://dx.doi.org/10.1111/j.1365-2788.1997.tb00689.x

Felce, D., \& Perry, J. (1995). Quality of life: Its definition and measurement. Research in Developmental Disabilities, 16(1), 51-74. http://dx.doi.org/10.1016/0891-4222(94)00028-8

Felce, D., \& Perry, J. (1996). Assessment of quality of life. In: R. L. Schalock, (Ed), Quality of life: Vol. 1. Conceptualisation and measurement. Washington, DC: American Association on Mental Retardation.

Fratini, R., \& Maroni, E. (2011). Green-space in urban areas: Evaluation of the efficiency of public spending for management of green urban areas. International Journal of E-Business Development, 1(1), 9-14.

Galloway, S. (2006). Quality of life and well-being: Measuring the benefits of culture and sport: A literature review. Edinburgh, Scotland: Scottish Executive Social Research.

Getter, K. L., \& Rowe, D. B. (2006). The role of extensive green roofs in sustainable development. Hortscience, 41(5), 1276-1285.

Godefroid, S., \& Koedam, N. (2003). Distribution pattern of the flora in a peri-urban forest: An effect of the city-forest ecotone. Landscape and Urban Planning, 65(4), 169-185. http://dx.doi.org/10.1016/S01692046(03)00013-6

Gomez, F., Gill, L., \& Jabaloyes, J. (2004). Experimental investigation on the thermal comfort in the city: Relationship with the green areas, interaction with the urban microclimate. Building and Environment, 39(9), 1077-1086. http://dx.doi.org/10.1016/j.buildenv.2004.02.001

Hagerty, M. R., Cummins, R. A., Ferriss, A. L., Land, K., Michalos, A. C., Peterson, M., ... Vogel, J. (2001). Quality of life indexes for national policy: Review and agenda for research. Social Indicators Research, 55(1), 1-96. http://dx.doi.org/10.1023/A:1010811312332

Harnik, P. (2004). The excellent park system: What makes it great and how to get there? San Francisco, CA: The Trust for Public Land.

Harvey, A. S. (1993). Quality of life and the use of time theory and measurement. Journal of Occupational Science, Australia, 1(2), 27-30. http://dx.doi.org/10.1080/14427591.1993.9686381

Holmes, S. (2005). Assessing the quality of life-reality or impossible dream? A discussion paper. International Journal of Nursing Studies, 42, 493-501. http://dx.doi.org/10.1016/j.ijnurstu.2004.06.014

Isenberg, J. P., \& Quisenberry, N. (2002). A position paper of the Association for Childhood Education International PLAY: Essential for all Children. Childhood Education, 79(1), 33-39. http://dx.doi.org/10.1080/00094056.2002.10522763

Jennings, V., Johnson-Gaither, C., \& Gragg, R. S. (2012). Promoting environmental justice through urban green space access: A synopsis. Environmental Justice, 5(1), 1-7. http://dx.doi.org/10.1089/env.2011.0007

Jim, C. Y., \& Chen, W. Y. (2006). Recreation-amenity use and contingent valuation of urban green spaces in Guangzhou, China. Landscape and Urban Planning, 75(1-2), 81-96. http://dx.doi.org/10.1016/j.landurbplan.2004.08.008

Jim, C. Y., \& Liu, H. T. (2001). Species diversity of three major urban forest types in Guangzhou City, China. Forest Ecology and Management, 146(1-3), 99-114. http://dx.doi.org/10.1016/S0378$\underline{1127(00) 00449-7}$

Johannesburg City Parks and Zoo (2014). Annual report 2013/14. Johannesburg, South Africa: Johannesburg City Parks and Zoo. 
Kabischa, N., \& Haase, D. (2014). Green justice or just green? Provision of urban green spaces in Berlin, Germany. Landscape and Urban Planning, 122, 129-139. http://dx.doi.org/10.1016/j.landurbplan.2013.11.016

Khan, K. S., Kunz, R., Kleijnen, J., \& Antes, D. (2003). Five steps to conducting a systematic review. Journal of the Royal Society of Medicine, 96(3), 118-121. http://dx.doi.org/10.1258/jrsm.96.3.118

Kim, J., \& Kaplan, R. (2004). Physical and psychological factors in sense of community: New urbanist Kentlands and nearby Orchard Village. Environment and Behaviour, 36(3), 313-340. http://dx.doi.org/10.1177/0013916503260236

Konijnendijk, C. C., Annerstedt, M., Nielson, A. B., \& Maruthaveeran, S. (2013). Benefits of urban parks: A systematic review. (Report to the International Federation of Parks and Recreation Administration, IFPRA,). Copenhagen, Denmark: IFPRA.

Kordowski, K., \& Kuttler, W. (2010). Carbon dioxide fluxes over an urban park area. Atmospheric Environment, 44(23), 2722-2730. http://dx.doi.org/10.1016/j.atmosenv.2010.04.039

Kottmeier, C., Biegert, C., \& Corsmeier, U. (2007). Effects of urban land use on surface temperature in Berlin: Case study. Journal of Urban Planning and Development, 33, 128-137. http://dx.doi.org/10.1061/(ASCE)0733-9488(2007)133:2(128)

Kuo, F. E, \& Sullivan, W. C. (2001). Environment and crime in the inner city: Does vegetation reduce crime? Environment and Behavior, 33(3), 343-367.

Land Use Consultants (2011). An assessment of the impacts of climate change on Scottish landscapes and their contribution to quality of life: Phase 1 - final report (Scottish Natural Heritage Commissioned Report No. 488). Inverness, Scotland: Scottish Natural Heritage

Land Use Consultants (2004). Making the links: green space and quality of life. Scottish Natural Heritage Commissioned Report No. 060 (ROAME No. F03AB01). Clydebank, Scotland: Scottish Natural Heritage.

Lindstrom, B. (1994). The essence of existence. On the quality of life of children in the Nordic countries - theory and practice in public health (Doctoral thesis). Nordic School of Public Health, Gothenburg, Sweden.

Lindstrom, B., \& Eriksson, M. (2010). A salutogenic approach to tackling health inequalities. In A. Morgan, E. Ziglio and M. Davis (Eds.), Health assets in a global context: Theory, methods, action (pp.1739). http://dx.doi.org/10.1007/978-1-4419-5921-8 2

Lloyd, K. M., \& Auld, C. J. (2002). The role of leisure in determining quality of life: Issues of content and measurement. Social Indicators Research, 57, 43-71. http://dx.doi.org/10.1023/A:1013879518210

Lorenzo, A. B., \& Wims, D. (2004). Do designed landscapes deter crime? Proceedings of the Florida State Horticultural Society, 117, 297-300.

Louv, R. (2005). Last child in the woods: Saving our children from nature-deficit disorder. Chapel Hill, NC: Algonquin Books.

Lowman, M. (2006). No child left indoors. Frontiers in Ecology and the Environment, 4(9), 451-451. http://dx.doi.org/10.1890/1540-9295(2006)4[451:NCLI]2.0.CO;2

Luttik, J. (2000). The value of trees, water and open spaces as reflected by house prices in the Netherlands. Landscape and Urban Planning, 48(3-4), 161-167. http://dx.doi.org/10.1016/S0169-2046(00)00039-6

Lutzenhiser, M., \& Netusil, N. (2001). The effect of open space on a home's sale price. Contemporary Economic Policy, 19(3), 291-298. http://dx.doi.org/10.1093/cep/19.3.291

Maas, J., Verheij, R. A., des Vries, S., Spreeuwenberg, P., Schellevis, F. G., \& Groenwegen, P. P. (2009). Morbidity is related to a green living environment. Journal of Epidemiology and Community Health, 63, 967-997. http://dx.doi.org/10.1136/jech.2008.079038

Manlun, Y. (2003). Sustainable analysis of urban green space system based on GIS. (Master's thesis). International Institute for Geo-information Science and Earth Observation, Enschede, Netherlands.

McPherson, E. G., \& Muchnick, J. (2005). Effects of street tree shade on asphalt concrete pavement performance. Journal of Arboriculture, 31(6), 303-310.

Meeberg, G. A. (1993). Quality of life: A concept analysis. Journal of Advanced Nursing, 18(1), 32-38. http://dx.doi.org/10.1046/j.1365-2648.1993.18010032.x 
Milligan, C., Gatrell, A., \& Bingley, A. (2004). Cultivating health: Therapeutic landscapes and older people in Northern England. Social Science \& Medicine, 58(9), 1781-1793. http://dx.doi.org/10.1016/S0277-9536(03)00397-6

Moons, P., Budts, W., \& De Geesta, S. (2006). Critique on the conceptualisation of quality of life: A review and evaluation of different conceptual approaches. International Journal of Nursing Studies, 43, 891-901. http://dx.doi.org/10.1016/j.ijnurstu.2006.03.015

Muldoon, M. F., Barger, S. D., Flory, J. D., \& Manuck, S. B. (1998). What are quality of life measurements measuring? British Medical Journal, 316(7130), 542-545. http://dx.doi.org/10.1136/bmj.316.7130.542

Nowak, D. J., Crane, D. E., \& Stevens, J. C. (2006). Air pollution removal by urban trees and shrubs in the United States. Urban Forestry \& Urban Greening, 4(3-4), 115-23. http://dx.doi.org/10.1016/j.ufug.2006.01.007

Paoletti, E., Bardelli, T., Giovannini, G., \& Pecchioli, L. (2011). Air quality impact of an urban park over time. Procedia Environmental Sciences, 4, 10-16. http://dx.doi.org/10.1016/j.proenv.2011.03.002

Rosenberg, R. (1995). Health related quality of life between naturalism and hermeneutics. Social Science and Medicine, 41, 1411-1415. http://dx.doi.org/10.1016/0277-9536(95)00123-O

Sandstrom, U. F. (2002). Green infrastructure planning in urban Sweden. Planning Practice and Research, 17(4), 373-385. http://dx.doi.org/10.1080/02697450216356

Saraev, V. (2012). Economic benefits of green space: A critical assessment of evidence of net economic benefits. (Forestry Commission Research Report). Edinburgh, Scotland: Forestry Commission.

Schalock, R. L. \& Verdugo, M. (2002). Handbook on quality of life for human service practitioners. Washington DC: American Association on Mental Retardation.

Sister, C., Wolch, J., \& Wilson, J. (2010). Got green? Addressing environmental justice in park provision. GeoJournal, 75(3), 229-248. http://dx.doi.org/10.1007/s10708-009-9303-8

Skevington, S. M., Lotfy, M. \& O'Connell, K. A. (2004). The World Health Organization's WHOQOLBREF quality of life assessment: Psychometric properties and results of the international field trial. A Report from the WHOQOL Group. Quality of Life Research, 13, 299-310.

http://dx.doi.org/10.1023/B:QURE.0000018486.91360.00

Sorensen, M., Smit, J., Barzetti, V., \& Williams, J. (1997). Good practice for urban greening. Washington, DC: Inter-American Development Bank.

Susniene, D., \& Jurkauskas, A. (2009). The concepts of quality of life and happiness: Correlation and differences. Inzinerine Ekonomika-Engineering Economics 3, 58-66.

Swanwick, C., Dunnett, N., \& Woolley, H. (2003). Nature, role and value of green space in towns and cities: An overview. Built Environment, 29(2), 94-106. http://dx.doi.org/10.2148/benv.29.2.94.54467

Takano, T., Nakamura, K., \& Watanabe, M. (2003). Urban residential environments and senior citizen's longevity in mega cities: The importance of walkable green spaces. Journal of Epidemiology and Community Health, 56, 913-918. http://dx.doi.org/10.1136/jech.56.12.913

Tanner, R. A., \& Gange, A. C. (2005). Effects of golf courses on local biodiversity. Landscape and Urban Planning, 71(2-4), 137-146. http://dx.doi.org/10.1016/S0169-2046(04)00034-9

Taylor, A. F., Kuo, F. E., \& Sullivan, W. C. (2001). Coping with ADD: The surprising connection to green play settings. Environment $\mathcal{E}$ Behavior, 33(1), 54-77. http://dx.doi.org/10.1177/00139160121972864

Testa, M. A., \& Simonson, D. C. (1996). Assessment of quality-of-life outcomes. The New England Journal of Medicine, 334(13), 835-840. http://dx.doi.org/10.1056/NEJM199603283341306

The Trust for Public Land. (2009). Measuring the economic value of a city park system. http://cloud.tpl.org/pubs/ccpe-econvalueparks-rpt.pdf

The Trust for Public Land (2008). How much value does the city of Philadelphia receive from its park and recreation system? Philadelphia, PA: The Trust for Public Land and Philadelphia Parks Alliance.

The Urban Green Spaces Taskforce (2002). Green spaces, better places (final report). London, United Kingdom: Department for Transport, Local Environment and the Regions.

The WHOQOL Group. (1995). The World Health Organization Quality of Life Assessment (WHOQOL): Position paper from the World Health Organization. Social Science and Medicine, 41(10), 1403-1409. http://dx.doi.org/10.1016/0277-9536(95)00112-K 
Tzoulas, K. K., Korpela, K., Venn, S., Yli-Pelkonen, V., Kazmierczak, A., Niemela, J., \& James, P. (2007). Promoting ecosystem and human health in urban areas using green infrastructure: A literature review. Landscape and Urban Planning, 81, 167-178. http://dx.doi.org/10.1016/j.landurbplan.2007.02.001

Uman, L. S. (2011). Systematic reviews and meta analyses. Journal of the Canadian Academy of Child and Adolescent Psychiatry, 20(1), 57-59.

United Nations Environment Programme. (2011). The environmental dimension of IFSD: Importance of environmental pillar to IFSD. Issues briefs \#1. Nairobi, Kenya: United Nations Environment Programme.

Ventegodt, S., Merrick, J., \& Anderson, N. J. (2003). Quality of life theory I. The IQOL theory: An integrative theory of the global quality of life concept. The Scientific World Journal, 3, 1030-1040. http://dx.doi.org/10.1100/tsw.2003.82

Victor, L. (2008). Systematic reviewing. Social Science Update, 58, 1-4.

Wolch, J. R., Byrne, J., \& Newell, J. P. (2014). Urban green space, public health, and environmental justice: The challenge of making cities 'just green enough'. Landscape \& Urban Planning, 125, 234-244. http://dx.doi.org/10.1016/j.landurbplan.2014.01.017

Woo, J., Tang, N., Suen, E., Leung, J., \& Wong, M. (2009). Green space, psychological restoration, and telomere length. Lancet, 373(9660), 299-300. http://dx.doi.org/10.1016/S0140-6736(09)60094-5

World Health Organisation. (2014). Climate change and health. http://www.who.int/mediacentre/factsheets/fs266/en/

World Health Organisation. (1997). Measuring quality of life: The World Health Organization quality of life Instruments (WHO/MSA/MNH/PSF/97.4). Geneva, Switzerland: World Health Organisation.

World Health Organisation. (1995). The World Health Organisation quality of life assessment (WHOQOL): Position paper from the WHO. Social Science and Medicine, 41, 347-352.

Xi-Zhang, S. (2009). Urban green spaces in Guangzhou (China): Attitude, preference, use pattern and assessment. (Doctoral thesis). The University of Hong Kong. 